\title{
TEORIA DE AUSUBEL E MAPAS CONCEITUAIS
}

\author{
Maria Inês de Affonseca Jardim*
}

\section{INTRODUÇÃO}

Ausubel é um psicólogo educacional da linha cognitivista que destaca a aquisição de conceitos claros, diferenciados e estáveis como fator preponderante na aprendizagem.

Pretendemos fazer, neste artigo, um resumo da Teoria de aprendizagem de David Ausubel e apresentar algumas das formas de aplicação desta teoria no processo de ensino e aprendizagem.

\footnotetext{
* Formada em Física pela Universidade Estadual de Londrina, PR, com pós-graduação (lato sensu) em Metodologia do Ensino da Ciência pela FUCMT, Campo Grande-/MS, Maria Inês de A. Jardim leciona no CESUP, Campo Grande-MS e cursa o programa de Mestrado na UCDB.
} 


\subsection{Introdução}

Ausubel é um representante do cognitivismo, teoria que se fundamenta na idéia de que o conhecimento é elaboração praticada pelo sujeito, diferente do inatismo ou empirismo que concebem-no ou como dado hereditário ou como resultado da pressão-estimulação do meio.

Para ele a aprendizagem resulta da ação, pelo indivíduo, de armazenar, organizadamente, as informações na mente que aprende. A este complexo organizado dá-se o nome de estrutura cognitiva, entendida como o conteúdo organizado total de conceitos de um indivíduo, ou conteúdo e organização conceitual de suas idéias, em uma determinada área particular de conhecimento (Moreira, 1981).

\subsection{Aprendizagem significativa e mecânica}

A idéia principal da teoria de Ausubel é a de aprendizagem significativa. Para ele esta aprendizagem é o processo através do qual uma nova informação relacionase com um aspecto relevante da estrutura de conhecimento do sujeito. A nova informação relaciona-se ou ancora-se em conceitos significativos ou relevantes preexistentes na 
estrutura cognitiva (conceito subsunçor ou simplesmente subsunçor). Esta relação é feita de maneira organizada e hierárquica, de tal forma que conceitos mais específicos de conhecimento são ligados (e assimilados) a conceitos mais gerais (inclusivos).

Diferente da aprendizagem significativa, pode acontecer a aprendizagem mecânica, que é aquela onde as novas informações têm pouca ou nenhuma associação com conceitos relevantes existentes na estrutura cognitiva do sujeito. Esta falta de relação pode-se dar por inexistência de conceitos subsunçores adequados. Quando esta aprendizagem ocorre, a nova informação é armazenada de maneira arbitrária, não havendo interação com conceitos subsunçores específicos.

Possuir conceitos subsunçores adequados é condição para que ocorra aprendizagem significativa.

Quando o aluno é capaz de transferir o conhecimento adquirido para situações novas e distintas, podemos dizer que temos evidências de uma aprendizagem significativa.

Para que esta aprendizagem significativa ocorra é necessário que o material a ser aprendido pelo aluno seja potencialmente significativo, relevante para a sua estrutura cognitiva. Alem disto, o aluno deve mostrar-se disposto a relacionar, de maneira substantiva e não arbitrária, a este material.

Segundo Ausubel (1978:41)

"a essência do processo de aprendizagem sig- 
nificativa é que idéias simbolicamente expressas sejam relacionadas de maneira substantiva e não arbitrária ao que o aprendiz já sabe, ou seja, a algum aspecto de sua estrutura cognitiva especificamente relevante para a aprendizagem dessas idéias. Este aspecto especificamente relevante pode ser, por exemplo, uma imagem, um símbolo, um conceito, uma proposição, já significativo."

Ausubel recomenda, o uso de organizadores prévios (materiais introdutórios apresentados antes do material a ser aprendido )" que sirvam como âncoras para a nova aprendizagem e levem ao desenvolvimento de conceitos subsunçores que facilitem a aprendizagem subseqüente" (Moreira, 1981). Estes materiais introdutórios seriam apresentados em um nível de abstração, generalização e inclusividade maiores que o material a ser apreendido pelo aluno.

\subsection{Tipos de aprendizagem significativa}

\subsubsection{Representacional}

É o tipo mais básico de aprendizagem significativa. Envolve a atribuição de significado a determinados símbolos (tipicamente palavras). Os símbolos (palavras) passam a significar para o indivíduo aquilo que seus referentes (objetos, eventos, conceitos) significam. 


\subsubsection{De Conceitos}

Podemos diferenciar dois tipos de aprendizagem de conceitos: a formação de conceitos e a assimilação de conceitos.

a) Formação de Conceitos: Consiste na aquisição espontânea e indutiva de idéias genéricas. É um tipo de aprendizagem por descoberta, onde aparecem processos psicológicos como a discriminação, a generalização, o levantamento e a comprovação de hipóteses. Este processo é próprio de crianças até $5 / 6$ anos. (Ronca, 1982).

b) Assimilação de Conceitos: É possível em crianças a partir de 6/7 anos, em adolescentes e adultos

"...que aprendem novos significados conceituais quando se lhes apresentam os atributos criteriais dos conceitos e quando eles relacionam esses atributos com idéias pertinentes estabelecidas em suas estruturas cognitivas" (Ronca, 1982).

"Portanto, a assimilação é um processo que ocorre quando um conceito ou proposição “ $a$ ", potencialmente significativo, é assimilado sob uma idéia ou conceito mais inclusivo, já existente na estrutura cognitiva como um exemplo, extensão, elaboração ou qualificação do mesmo" (Moreira e Buchweitz, 1987). 


\subsubsection{Proposicional}

Normalmente, as palavras combinadas em uma sentença para constituir uma proposição representam conceitos. A aprendizagem proposicional consiste em aprender o significado das idéias expressas, verbalmente, através desses conceitos, sob forma de proposição. (Moreira, 1981).

"Na aprendizagem proposicional, a tarefa de aprendizagem significativa não se reduz ao aprendizado do que representam as palavras isoladamente ou à combinação das mesmas; refere-se, antes de tudo, ao aprendizado do significado de novas idéias expressas de forma proposicional' (Ausubel-Novak-Hanesian, 1980).

Quando esta aprendizagem ocorre, a sentença a ser aprendida é relacionada com idéias já existentes na estrutura cognitiva. Este relacionamento pode ser :

a) Subordinado: a aprendizagem subordinada pode se dar por subsunção derivativa, que ocorre quando a proposição é, simplesmente, um exemplo ou uma forma de ilustrar uma proposição mais inclusiva, já estabelecida na estrutura cognitiva, ou subsunção correlativa, onde as novas proposições são uma extensão, elaboração, modificação de proposições, previamente, aprendidas.

b) Super-ordenado: quando a nova proposição abrange várias idéias já estabelecidas na estrutura cognitiva, reordenandoas. Ocorre através do raciocínio indutivo. Este tipo de aprendizagem é mais comum na aprendizagem conceitual. 
c) Relação Combinatória: neste tipo de aprendizagem não existe uma relação de subordinação ou superordenação entre as idéias novas apreendidas e idéias, particularmente, relevantes da estrutura cognitiva. Estas proposições

"são potencialmente significativas porque consistem de combinações sensiveis de idéias previamente aprendidas que podem relacionar-se não arbitrariamente ao amplo armazenamento de conteúdo, geralmente relevante, na estrutura cognitiva, em virtude de sua congruência geral com este conteúdo como um todo" (Ausubel-Novak-Hanesia, 1980).

\subsection{Diferenciação progressiva e reconciliação inte- grativa}

Quando um conceito é aprendido por subordinação, ele interage ou relaciona-se com um subsunçor, já existente na estrutura cognitiva. Esta interação provoca uma modificação também no conceito subsunçor. Esta modificação, uma ou mais vezes do conceito subsunçor, leva a diferenciação progressiva deste conceito.

Para Ausubel a diferenciação progressiva pode ser vista como um princípio programático para a organização e seleção da matéria de ensino, segundo o qual as idéias, conceitos, proposições mais gerais e inclusivos do conteúdo devem ser apresentados no início da instrução e, progressivamente, diferenciados em termos de detalhes e especificidade. 
Quando a aprendizagem de um novo conceito provoca, na estrutura cognitiva, uma reordenação dos elementos, previamente existentes nesta estrutura, temos uma reconciliação integrativa. Este processo normalmente ocorre na aprendizagem superordenada e combinatória (Moreira, 1981).

A reconciliação progressiva deve ser, também, considerada como princípio para a seleção e organização dos conteúdos de ensino.

Apesar da diferenciação progressiva estar mais relacionada com a aprendizagem subordinada e a reconciliação integrativa com as aprendizagens superordenada e combinatória, sempre que ocorre uma aprendizagem significativa, teremos uma reconciliação integrativa, que é uma forma de diferenciação progressiva da estrutura cognitiva.

Segundo Ausubel, esses dois princípios programáticos podem ser implementados, na prática, através do uso de organizadores prévios. Podemos também provocar a diferenciação progressiva e a reconciliação integrativa através de mapas conceituais.

\section{MAPAS CONCEITUAIS}

Mapas conceituais são diagramas hierárquicos bidimensionais, indicando os conceitos e as relações entre esses conceitos para uma fonte de conhecimento e derivam sua existência da própria estrutura da fonte (Moreira, 1987).

Existem várias maneiras de se traçar um mapa 
conceitual, já que podemos representar um hierarquização de vários modos. Logo, mapas conceituais são instrumentos flexíveis, que não podem ser considerados únicos para um determinado assunto.

O modelo de um mapa conceitual, baseado na teoria de David Ausubel, terá os conceitos mais gerais e inclusivos no topo da hierarquia, e os mais específicos e pouco abrangentes na base. As linhas procuram representar relações proposicionais significativas entre conceitos.

Este tipo de representação e relacionamento de conceitos pode ser aplicado como instrumento de avaliação de aprendizagem, organizador de conteúdos e currículos, reorganizadores de conceitos apresentados em laboratório, etc.

Os mapas conceituais facilitam a organização e o relacionamento de conceitos novos a serem apresentados em uma aula ou curso, com conceitos subsunçores já existentes na estrutura cognitiva do aluno. Destacam relações de subordinação e de superordenação. São representações claras da estrutura conceitual, que está sendo ensinada, logo facilitam a aprendizagem desta estrutura.

Normalmente, são obedecidos os seguintes passos na elaboração de um mapa conceitual (Moreira, 1987):

\section{Localizam-se os conceitos.}

2. Listam-se os conceitos em uma ordem hierárquica.

3. Distribuem-se os conceitos em duas dimensões.

4. Traçam-se as linhas que indicam as relações entre os conceitos. 
5. Escreve-se a natureza da relação.

6. Prepara-se o mapa final.

$\mathrm{Na}$ figura 1, temos um modelo de como mostrar a estrutura conceitual de uma matéria, usando mapas conceituais, e na figura 2, um exemplo de mapa conceitual para o texto de A. C. C. Ronca: O modelo de ensino de David Ausubel.

\section{O MAPA CONCEITUAL PARA A ANÁLISE E PLANE- JAMENTO DO CONTEÚDO DE ENSINO}

Cada disciplina, livro, artigo, experimento, currículo, refere-se a um conjunto de conhecimento, conceitos e relações entre eles, ou seja, uma "estrutura de conhecimento" ou estrutura cognitiva de matéria de ensino.

Para alcançarmos uma aprendizagem significativa, é necessário, como já vimos, que os novos conceitos relacionem-se de maneira relevante com conceitos existentes na estrutura cognitiva do aluno (subsunçores), logo quando estivermos organizando uma disciplina, um curso, uma aula, devemos nos preocupar em relacionar os novos conceitos com os subsunçores já existentes.

Ao organizarmos o conteúdo de ensino de uma disciplina, estamos lidando com um enorme conjunto de informações que devem ser apreendidas. Destas informações, apenas algumas são gerais e servirão como base para uma ampla variedade de situações de aprendizagem. Segundo Ausubel, as proposições mais gerais e importantes devem ser introduzidas pri- 
CONCEITOS MAIS GERAIS SUPERORDENADOS, MUITO ABRANGENTES

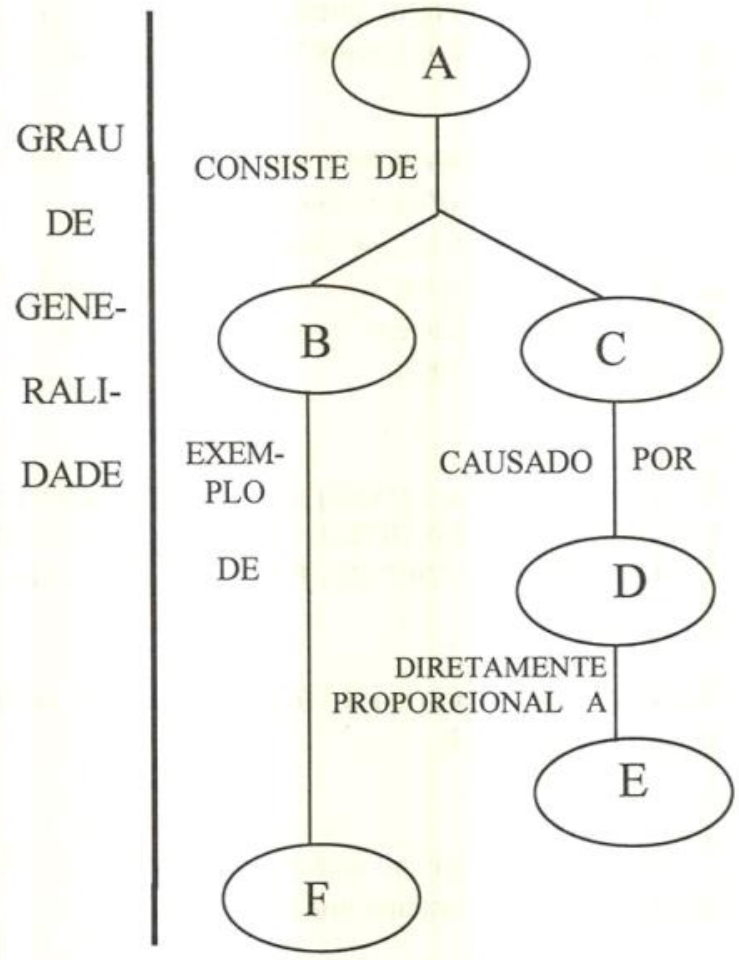

Fig. 1 -Modelo simples de mostrar a estrutura conceitual usando a técnica de mapeamento conceitual (Moreira, 1987). 
meiro, servindo para facilitar a aprendizagem significativa de um número grande de informações e, também, facilitando o aprendizado de conceitos subordinados.

Não podemos, porém, ignorar o nível de desenvolvimento cognitivo do aluno, e seu "estoque" de conceitos subsunçores.

"É mais importante determinar os conceitos disponiveis que os alunos têm para uma aprendizagem significativa em qualquer área do que tentar fazer o ensino aderir a alguma "hierarquia de aprendizagem" relativamente arbitrária" (Ausubel, 1980).

\section{PROPOSTA DE MAPA CONCEITUAL DO CURRÍCULO} DA DISCIPLINA FÍSICA GERAL I DOCURSO DE ENGENHARIA CIVIL DO CESUP, NA PARTE DE MECÂNICA

4.1 Conteúdo programático de física geral I do curso de engenharia civil

O programa de ensino está proposto, como se observa abaixo, de modo bastante linear:

- Como medir grandezas físicas

- SI e transformação de unidades

- Comprimento, tempo e massa

- Movimento retilíneo 


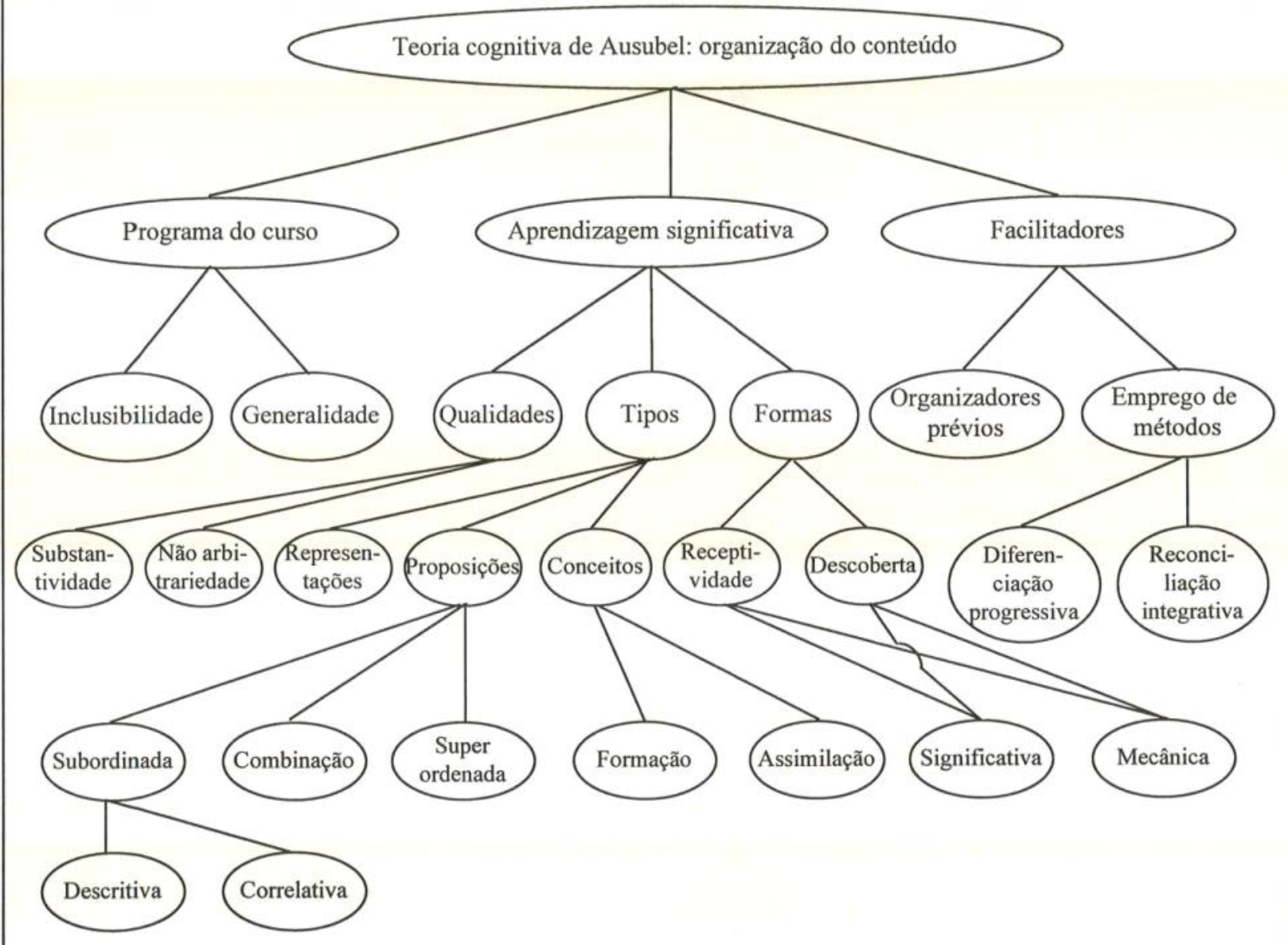

Fig. 2 - Mapa Conceitual do Texto: O Modelo de Ensino de David Ausubel de Ronca A. C. C. 
- Cálculo vetorial

- Movimento de um projétil

- $\mathrm{MCU}$

- $1^{\mathrm{a}}, 2^{\mathrm{a}}, 3^{\mathrm{a}}$ leis de Newton, força e massa

- Massa e peso

- Aplicações das leis de Newton

- Atrito, leis de atrito

- Trabalho

- Energia

- Leis da conservação da energia

- Movimento linear, centro de massa

- Colisões

- Movimento de rotação

- Movimento angular

\subsection{Proposta de mapa conceitual da disciplina}

Sugere-se este mapa onde os conceitos e relações entre eles são explicados.

Analisando-se a proposta de organização do programa de Física do $1^{\circ}$ ano do curso de Engenharia Civil, segundo o mapa conceitual indicado, tem-se que: 
a) No estudo da Mecânica Newtoniana existem leis e princípios gerais, que são válidos, também, para a mecânica de altas velocidades e mecânica de partículas subatômicas. Como exemplos, temos o princípio da conservação da energia e a lei da conservação do momento linear.

b) As leis de Newton estão direta ou indiretamente ligadas a todos os conceitos estudados na mecânica Clássica, já que são as leis que descrevem o movimento, à baixa velocidade, de corpos não subatômicos.

c) $\mathrm{O}$ conceito de movimento linear é semelhante à segunda lei de Newton, podendo ser escrito em função dela, e vice-versa:

$$
\sum \mathrm{F}_{\text {ext }}=\mathrm{dP} / \mathrm{dt} \text { ou } \sum \mathrm{F}_{\text {ext }}=\mathrm{M} \cdot \mathrm{a}_{\mathrm{cm}}
$$

d) Todos os estudos dos tipos de movimentos particulares, feitos na cinemática uni e bidimensionais, passam movimentos precisamos destas leis.

e) Os conceitos mais inclusivos da mecânica clássica são os de conservação de energia, conservação do momento e leis de Newton, portanto procurando realizar um estudo da programação de conteúdo, segundo a diferenciação progressiva proposta por Ausubel, estes conceitos devem ser os primeiros a serem estudados, uma vez que possuem maior inclusividade. No entanto, para que o aluno possa ter uma aprendizagem significativa, é necessário que conheça alguns conceitos subsunçores como velocidade, repouso, deslocamento, aceleração, tempo e conhecimentos básicos de matemática. 


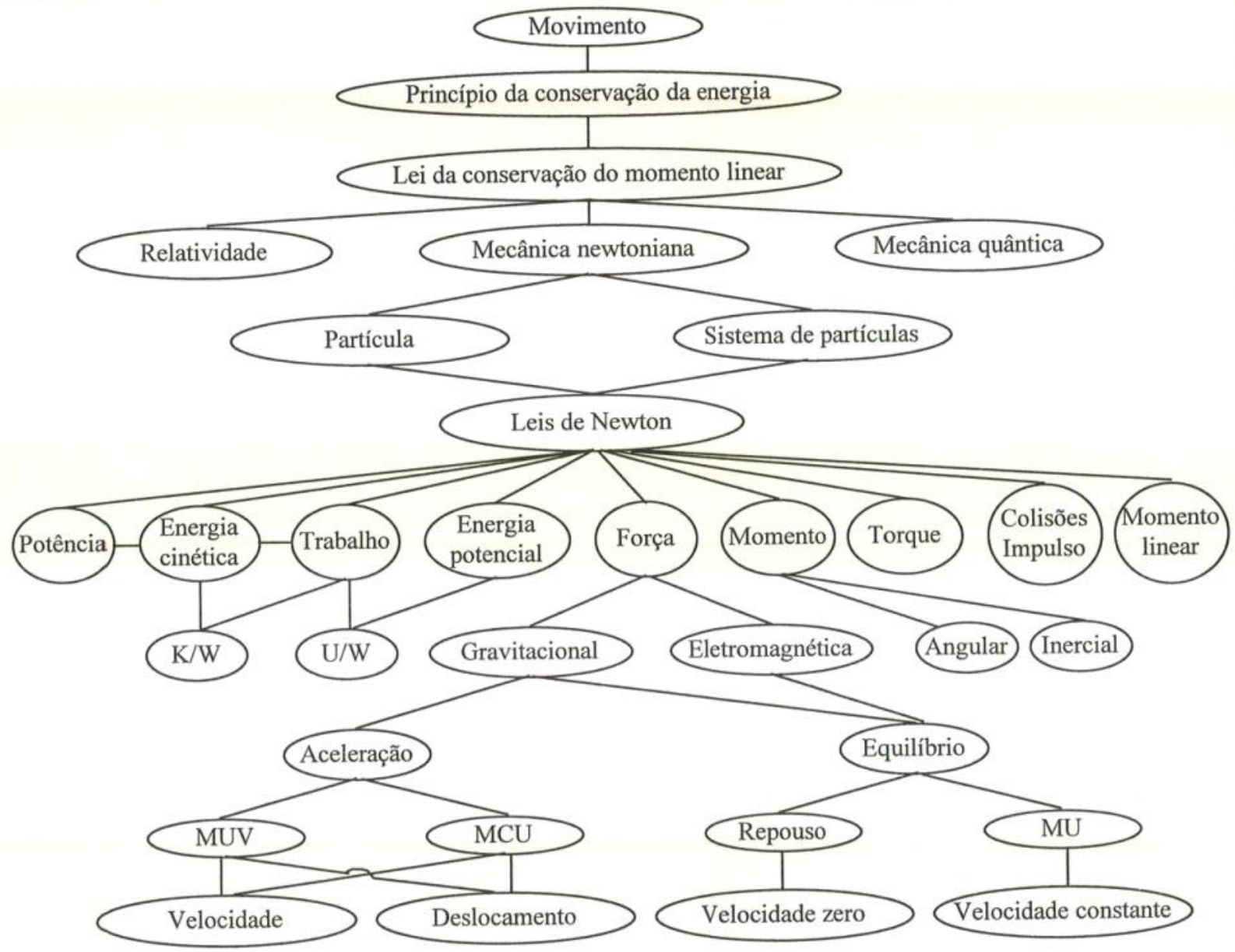

Fig. 3 - Mapa conceitual do currículo da disciplina Física Geral I do Curso de Engenharia Civil do CESUP 
rante todo o curso, já que a todo momento podemos relacionar os conceitos estudados com as leis de Newton e com a conservação de energia, comparando-os, diferenciando-os e relacionando-os.

\section{CONCLUSÃo}

Podemos traçar mapas conceituais com vários intuitos. Eles podem ser usados como instrumentos de ensino, de avaliação da aprendizagem ou na análise e planejamento de ensino e curricular.

No programa do conteúdo de ensino de um curso, os mapas conceituais são muito úteis para enfatizar os conceitos mais abrangentes e integradores, orientando o professor no sentido de que ele possa dar ênfase aos assuntos mais gerais e abrangentes de sua disciplina. Além disto, os mapas conceituais podem ser usados pelos professores e alunos para clarificar e encontrar relações entre conceitos e leis já estudados.

Para o curso de Engenharia Civil do CESUP (Centro de Ensino Superior Prof. Plínio Mendes dos Santos), o mapa conceitual da disciplina Física Geral I teve como utilidade, além das citadas acima, a de relacionar as disciplinas de Física Geral e Mecânica, já que as duas são ministradas no primeiro ano e têm enfoques diferentes, o que causa uma certa confusão para os alunos.

Poderíamos também ter uma maior coesão entre os conteúdos estudados na disciplina de Física Geral I, nos 
diferentes cursos de Engenharia do CESUP, se, no planejamento das aulas, os professores trabalhassem em cima de um mapa conceitual comum a todos. Poderiam enfatizar os mesmos conceitos, tornando o ensino desta disciplina realmente básico e semelhante para todos os cursos.

\section{REFERÊNCIAS BIBLIOGRÁFICAS}

AUSUBEL, J. D., HANESTAN, H. Educational, psychology: a cognitive view. New York : Holt, Rinehort \& Winston, 1978.

BUCHWEITZ. Mapas conceituais: instrumentos didáticos de avaliação de análise de currículo. São Paulo : Editora Moraes, 1987.

MOREIRA, M. A. Melhorias do ensino. Ensino e aprendizagem: a teoria de Ausubel. n 15, 1981. (versão preliminar).

NOVAK Joseph, HANESIA Helen. Psicologia educacional. Rio de Janeiro : Editora Interamericana, 1980.

RONCA, A. C. C. O Modelo de Ensino de David Ausubel. In: MILAN, Josefina. Psicologia. São Paulo : Papelivros, 1982. 